\title{
Left Ventricular Basal Inferior Segment
}

National Cancer Institute

\section{Source}

National Cancer Institute. Left Ventricular Basal Inferior Segment. NCI Thesaurus. Code C127658.

The inferior portion of the basal division of the left ventricular myocardium as determined using the AHA 17-Segment Model (Cerqueira et al., 2002). 